\title{
Erratum to: A case-based reasoning based multi-agent cognitive map inference mechanism: An application to sales opportunity assessment
}

\author{
Namho Lee • Jae Kwon Bae • Chulmo Koo
}

Published online: 24 July 2012

(C) Springer Science+Business Media, LLC 2012

\section{Erratum to: Inf Syst Front \\ DOI 10.1007/s10796-011-9294-0}

The affiliations of Dr. Bae and Dr. Koo appeared incorrectly in the article cited above. The present affiliations are as follows:

The online version of the original article can be found at http://dx.doi.org/ 10.1007/s10796-011-9294-0.

\footnotetext{
N. Lee

Consulting Group, SAP Korea,

Dogok 2-dong, Kangnam-gu,

Seoul 135-700, Republic of Korea

e-mail: nam.ho.lee@sap.com

\section{J. K. Bae}

Department of Management Information Systems,

Keimyung University,

1095 Dalgubeoldaero, Dalseo-gu, Daegu 704-701,

Republic of Korea

e-mail: jkbae99@kmu.ac.kr

C. $\mathrm{Koo}$

Department of Convention Business,

The College of Hotel \& Tourism Management,

Kyung Hee University,

Seoul, South Korea

C. $\operatorname{Koo}(\bowtie)$

Kyung Hee Daero 26, Heogi-dong, Dongdeamun-gu,

Seoul 130-701, South Korea

e-mail: helmetgu@khu.ac.kr
} 